\title{
O tempo no processo de trabalho em saúde: uma abordagem sociológica*
}

\author{
Time in the health-related work process: a sociological approach \\ El tiempo en el proceso de trabajo en salud: un abordaje sociológico

\section{Maria Cristina de Mello', Fernanda Maria Togeiro Fugulin², Raquel Rapone Gaidzinski ${ }^{3}$}

\section{RESUMO}

O conceito de tempo, do qual fazemos uso, situa-se em um alto nível de generalização e de síntese, sendo um dos mais ricos patrimônios sociais do saber. Percebe-se, ao longo da evolução humana, que a concepção do tempo passa por vários estágios, iniciando como uma forma cíclica, descontínua e qualitativa, até assumir o sentido linear, progressivo e quantitativo, quando surge o sentimento de irreversibilidade. O tempo tem merecido destaque especial, principalmente no campo das ciências humanas e sociais, pois descobriu-se o seu valor nas organizações, isto é, no trabalho e também fora dele. A descoberta desse valor tornou-o um elemento chave na gestão de recursos das organizações, contribuindo tanto para o desempenho individual, quanto coletivo. Portanto, este artigo propõe uma reflexão sobre o tempo no trabalho, dentro de uma perspectiva sociológica, correlacionando-o com o desenvolvimento e evolução da sociedade, bem como com o processo de trabalho em saúde.

Descritores: Administração de pessoal; Gerenciamento do tempo; Eficiência organizacional

\begin{abstract}
The current concept of time is placed in a high level of generalization and synthesis, and is considered one of the most valuable resources of knowledge. As with human evolution, the concept of time goes through several stages. Initially time was understood as a cyclical, irregular, and qualitative concept. Later, with the advent of irreversibility, the concept of time became linear, progressive, and quantitative. Because of the importance of the concept of time within and outside of the work environment of an organization, time has been given special attention by the human and social sciences. This fact has become a key-element in the management of resources of an organization, contributing to improvement in individual and group performance. Therefore, this paper discusses work-related time from a sociological perspective and its relationship to the development and evolution of society. In addition, this paper also discusses the health-related work process.
\end{abstract}

Keywords: Resource management; Time management; Organizational; Efficiency

\section{RESUMEN}

El concepto de tiempo, del cual hacemos uso, se sitúa en un alto nivel de generalización y de síntesis, siendo uno de los más ricos patrimonios sociales del saber. Se percibe, a lo largo de la evolución humana, que la concepción del tiempo pasa por varias fases, iniciándose de una forma cíclica, discontinua y cualitativa, hasta asumir el sentido lineal, progresivo y cuantitativo, cuando surge el sentimiento de irreversibilidad. El tiempo ha merecido destaque especial, principalmente en el campo de las ciencias humanas y sociales, pues se descubrió su valor en las organizaciones, es decir, en el trabajo y también fuera de él. El descubrimiento de ese valor lo convirtió en un elemento clave en la gestión de recursos de las organizaciones, contribuyendo tanto para el desempeño individual, cuanto para el colectivo. Por tanto, este artículo propone una reflexión sobre el tiempo en el trabajo, dentro de una perspectiva sociológica, correlacionándolo con el desarrollo y evolución de la sociedad, así como con el proceso de trabajo en salud.

Descriptores: Administración de personal; Administración del tiempo; Eficiencia organizacional

\footnotetext{
${ }^{*}$ Trabalho extraído da dissertação de mestrado apresentada à Escola de Enfermagem da Universidade de São Paulo - USP - São Paulo (SP), Brasil;

${ }^{1}$ Mestre em Enfermagem; Gerente de Enfermagem do Hospital Iguatemi - São Paulo (SP), Brasil.

${ }^{2}$ Professora do Departamento de Orientação Profissional da Escola de Enfermagem da Universidade de São Paulo - USP - São Paulo (SP), Brasil.

${ }^{3}$ Professora Associada do Departamento de Orientação Profissional da Escola de Enfermagem da Universidade de São Paulo - USP - São Paulo (SP), Brasil;

Diretora do Departamento de Enfermagem do Hospital Universitário - Universidade de São Paulo - USP - São Paulo (SP), Brasil.
} 


\section{INTRODUÇÃO}

A descoberta sobre o valor do tempo no funcionamento das organizações tem permitido compreender melhor o fator tempo na vida, no trabalho ou fora dele, principalmente no Ocidente, principal campo de estudo sobre a temporalidade ${ }^{(1)}$.

O conceito de tempo, do qual fazemos uso, situa-se em alto nível de generalização e de síntese, sendo um dos riquíssimos patrimônios sociais do saber, no que diz respeito aos métodos de mensuração das seqüências temporais e as regularidades com que se apresentam, tendo esse saber exigido muito tempo para ser desenvolvido ${ }^{(2)}$.

Percebe-se, com o desenvolvimento da sociedade, que a concepção do tempo percorre vários estágios, passando por uma forma cíclica, descontínua e qualitativa, até assumir um sentido linear, progressivo e quantitativo.

Nesse momento o tempo passa a ter uma relação estreita com o trabalho, constituindo-se em um dos recursos fundamentais de uma organização. Assim, verifica-se que sua gestão contribui para a melhoria dos processos de trabalho, dos desempenhos coletivo e individual e, conseqüentemente, da produtividade.

Diante dessas considerações e da importância do tema, o presente trabalho tem por objetivo realizar uma reflexão sobre o tempo, no contexto do trabalho, correlacionandoo com o desenvolvimento e evolução da sociedade, bem como com o processo de trabalho em saúde.

\section{A CONCEPÇÃO DO TEMPO NO CAMINHAR DA SOCIEDADE}

As sociedades primitivas tinham, como instrumentos de medição de tempo, os movimentos do sol, da lua e das estrelas, sem relacionar os múltiplos movimentos dos corpos celestes em uma representação integrada e unitária. As atividades eram coletivas, a medição do tempo mantinha uma relação com a natureza e, portanto, o tempo era passivamente determinado, isto é, mal chegava a se experimentar sua determinação e tampouco a se refletir sobre ele.

Essa situação começou a modificar-se quando o homem passou a produzir seu próprio alimento, pois aí, ele precisava dominar e explorar o mundo vegetal, através de uma disciplina nunca experimentada anteriormente e, então, a determinação outrora passiva do tempo, passou a ser ativa.

A concepção do tempo, nesse estágio, era cíclica, descontínua e qualitativa, refletindo o tempo natural, onde a alternância do dia e da noite, assim como as estações do ano regiam a atividade produtiva, que era agrícola.

Segundo Elias (2) "a experiência do tempo como fluxo uniforme e contínuo só se tornou possivel através da medição do tempo, pelo estabelecimento progressivo de uma grade relativamente bem integrada de reguladores temporais, como os relógios de movimento continuo, a sucessão contínua dos calendários e as eras que encadeiam os séculos..."

Dessa forma, quando o homem substitui os movimentos do sol, da lua e das estrelas, por instrumentos de sincronização, como o relógio, a concepção do tempo, passa a ter um sentido linear, progressivo, quantitativo e surge o sentimento de irreversibilidade, sugerindo que o tempo seria um objeto físico mensurável, comparado a um rio, a uma montanha.

A determinação do tempo aparece como um meio de orientação, elaborado pelos homens, com o objetivo de realizar certas tarefas sociais muito precisas. A palavra tempo, simbolicamente, significa para Elias ${ }^{(2)}$ : “... a relação que um grupo bumano, ou qualquer grupo de seres vivos, dotado de uma capacidade biológica de memória e sintese, estabelece entre dois ou mais processos, um dos quais padronizado para servir aos outros como quadro de referência e padrão de medida..."

Isso corrobora a idéia, de que não há uma intuição única do tempo, comum a toda a humanidade, uma vez que as civilizações mais avançadas atribuem diferentes graus de significação ao modo temporal de existência. O tempo é considerado de muitas maneiras, conceitualmente distintas, com certeza, por se tratar de uma relação de homens dotados de experiências e objetivos os mais diversos possíveis ${ }^{(3)}$.

$\mathrm{O}$ advento do relógio mecânico influenciou socialmente o mundo, surgindo no século XIII, mas se multiplicando pela Europa somente no século XIV, quando foram instalados em praças públicas.

Percebe-se, então, o início da estreita relação entre o tempo e o trabalho, que se estabelece com o passar dos anos, por que não dizer, dos séculos.

Para Keith Tomas, citado por Whitrow ${ }^{(3)}$ : “... essa mudança nos hábitos de trabalho constituiu um importante passo rumo à aceitação social da noção moderna de tempo como igual em qualidade, em oposição ao antigo sentido da desigualdade e irregularidade do tempo...", sabendo-se que, nos tempos mais primitivos, o homem tinha períodos em que o trabalho era intenso e em outros eram cobertos pela ociosidade.

Mas, é com a revolução industrial que se estabeleceram, de fato, novas relações entre o tempo e o trabalho. Com a industrialização, o homem aprendeu um novo espaço de trabalho, onde desenvolveria sua atividade produtiva, a fábrica. Esse espaço foi marcado por um quadro temporal, através do ritmo das máquinas e dos limites da jornada de trabalho. O trabalho deixou de ser exercido como uma tarefa a ser desenvolvida no tempo natural, e o espaço de trabalho, que antes se confundia com o espaço privado, onde o artesão tinha seu ateliê juntamente com sua moradia, passou para um local específico, destinado exclusivamente para o desenvolvimento das atividades produtivas, reguladas pelo relógio, isto é, por um tempo mecânico. 
Atribuiu-se ao relógio um processo decisivo na era industrial e não à máquina a vapor, a qual foi atribuída tal importância. A confirmação de que o relógio foi o principal instrumento no trabalho social, por possuir as funções de coordenação e controle, pode ser atestada pela afirmação: "...o funcionamento das grandes empresas de produção exigia uma fragmentação temporal e espacial extremamente arrojadas tanto dos produtos como das atividades; tal especialização, por sua vez, tornava necessária uma coordenação temporal e espacial muito precisa, tanto no interior de cada empresa como nas suas relações com outras empresas. Uma coordenação precisa supunba, ela própria, um alto grau de planejamento e, para isso, era necessário construir um quadro temporal preciso. A exatidão das precisões dependia da medida do tempo, e uma organização eficaz, implicava em uma avaliação precisa da produtividade relacionada ao tempo. Enquanto o trabalho organizava-se em torno das máquinas, o planejamento organizava-se em torno dos horários" (4).

A disciplina do tempo de trabalho é imposta pela empresa e se transforma no principal instrumento que permite a aprendizagem, pelos operários, do quadro temporal do trabalho. A economia do tempo e a distribuição programada do tempo de trabalho nos diferentes ramos da produção permanecem como a primeira lei econômica básica da produção social ${ }^{(5)}$.

No final do século XIX e início do século XX, nos Estados Unidos, sob a influência de Taylor e seus seguidores, a organização científica do trabalho busca um outro tipo de abordagem para o ambiente industrial, tendo como essência o sistema de máquinas justaposto aos operários, procurando enfocar a produção com resultados que podiam variar, de acordo com a organização que era estabelecida pela atividade administrativa.

Dentre os aspectos da organização e da administração de uma empresa, o tempo, ou melhor, os tempos, ocupam um lugar de destaque. Taylor, segundo Schoeps ${ }^{(0)}$, direciona seus estudos para o conteúdo do tempo de trabalho e aos ritmos nos quais ele acontece, colocando como um dos pontos centrais de sua administração, chamada de administração científica, a introdução do cronômetro e a divisão do trabalho em fases ou elementos de trabalho, que serão medidos separadamente e servirão como base para determinar o tempo mínimo ou o tempo padrão de uma atividade, a fim de manter um ritmo e um nível de produção. $\mathrm{Na}$ época, seu sistema foi muito utilizado para combater a queda de ritmos na produção, que era um problema generalizado, e para estimular a produtividade dos operários, pois nessa proposta era aplicado um incentivo salarial, chamado de salário-prêmio.

Logo em seguida, surgem outros estudos de movimentos de operários na indústria da construção civil. A partir de então, o estudo dos tempos e movimentos na organização do trabalho das empresas se difundiu rapidamente sendo utilizado, até hoje, nas modernas empresas, para determinar os custos de uma operação.

\section{O TEMPO NO CONTEXTO DO TRABALHO EM SAÚDE}

$\mathrm{Na}$ discussão sobre a organização do trabalho e a concepção quantitativa do tempo, o tempo de trabalho medido precisamente transforma-se em um elemento chave para a empresa, que empenha-se em maximizar o rendimento simultâneo das máquinas e do tempo dos homens que lhe são justapostos ${ }^{(5)}$.

Diante dessa constatação, pode-se afirmar que o tempo é um fator determinante no trabalho e, conseqüentemente, na produtividade do trabalhador, seja qual for a tarefa desempenhada.

A produtividade pode ser definida como a relação entre a quantidade de produtos ou serviços produzidos e a quantidade de recursos utilizados. Os trabalhadores da produção ou dos serviços, chamados de mão-de-obra direta, representam parte desses recursos, sendo responsáveis pelo custo predominante da produção ${ }^{(7)}$.

A busca incessante por melhores métodos e processos de trabalho, com o objetivo de manter uma relação favorável de custo/beneficio, mostra que a produtividade é uma dimensão que está presente em qualquer tipo de atividade, seja qual for o setor. Inseridas no sistema de produção e, mais especificamente, no setor terciário da economia, encontram-se as organizações de saúde.

As organizações de saúde, como qualquer outro tipo de organização, necessitam de ferramentas que sejam capazes de instrumentalizar as tomadas de decisão relacionadas ao controle de custos. Esse controle vem possibilitar medidas de ajuste e de correção para a melhoria da qualidade, aumento da produtividade e otimização de recursos. Em uma empresas os custos podem ser reduzidos, quando houver melhora na eficiência, na produtividade e no uso do capital, mas se faz importante, também, a melhoria da qualidade nas operações produtivas, a fim de poder assegurar, ao usuário, que o produto ou o serviço esteja adequado ao seu propósito ${ }^{(8)}$, ficando evidente principalmente em uma organização de saúde, a produtividade e a qualidade dos processos e dos produtos caminham associados.

$\mathrm{Na}$ produção em saúde, o trabalho representa um componente de maior complexidade, pois é um fator de produção que não existe por si mesmo, mas sim, agregado aos agentes que o realizam, que são seres dotados de emoção e vontade, dentro de uma organização, assumindo papéis de verdadeiros arquitetos na construção da prática diária.

Os serviços, de maneira geral, possuem uma característica bastante peculiar que é a de serem consumidos no momento da produção. Essa característica é especialmente retratada no trabalho assistencial em saúde, que é prestado diretamente do produtor ao consumidor, ou na forma de trabalho coletivo prestado por instituições 
públicas e/ou privadas ${ }^{(9)}$.

Frente a esse cenário, verifica-se que uma das grandes dificuldades inerentes ao setor saúde refere-se à mensuração objetiva do valor do seu produto e dos resultados decorrentes de suas ações, por passar pela questão das diferenças de julgamento, de valores, percepções e preferências subjetivas. Outra dificuldade que pode ser apontada diz respeito à aferição da produtividade do setor saúde, devido a fatores como a heterogeneidade de seus processos de produção e a própria diversidade dos produtos ${ }^{(10)}$.

\section{CONSIDERAÇÕES FINAIS}

A percepção do tempo, enquanto fator decisivo na organização do trabalho, facilita a compreensão da relação deste com o processo de produção. Conseqüentemente, também auxilia a compreender o trabalho no processo de produção em saúde.

Analisar a produção de serviços em uma área como um hospital, que tem como produto principal a saúde do indivíduo, isto é, a recuperação/manutenção e melhora do estado de saúde e que sofre alterações de forma constante, é uma tarefa bastante complexa, pois os processos ou procedimentos realizados são submetidos aos mais variados impactos e atingem a instituição como um todo, mas principalmente o usuário, que também se apresenta aos serviços da forma mais simples e singular, ante a mais complexa, dando um caráter de imprevisibilidade ao setor, ao contrário de outros serviços, como por exemplo, uma indústria automobilística, onde o número de fatores intervenientes são bastante reduzidos e controlados na linha de produção. Portanto, essa dificuldade de aferição da produtividade se dá face à complexidade e diversificação de áreas de produção ${ }^{(11)}$.

A aplicação das tecnologias nas indústrias reduziu o recurso mais caro de uma empresa, a mão-de-obra. Nos hospitais, ou melhor, na área da saúde, essa teoria não se aplica com a mesma intensidade, uma vez que o elemento humano exerce uma forte influência na produção e qualidade dos serviços, não podendo ser substituído pelas máquinas, em sua maioria.

Existem fatores importantes que afetam o desenvolvimento do processo de trabalho em saúde, tais como: o tempo gasto no desempenho de atividades; a motivação e o desempenho do trabalhador; o uso da tecnologia, máquinas e ferramentas e os métodos de trabalho que sustentam e auxiliam o desenvolvimento do trabalho e a qualidade da assistência prestada ${ }^{(12)}$. Esse complexo conjunto de fatores dá um caráter de ingovernabilidade ao processo de trabalho na saúde, tornando portanto difícil, a mensuração do tempo efetivo de trabalho.

Assim, faz-se necessário a busca de uma ferramenta efetiva capaz de desvendar o tempo no trabalho em saúde e indicar o caminho que possibilite o desenvolvimento de uma proposta metodológica que auxilie o planejamento e avaliação do uso do tempo do trabalhador da área da saúde, no desempenho de suas atividades.

\section{REFERÊNCIAS}

1. Kamdem E. Tempo de trabalho na África. Traduzido por Tôrres OLS. In: Chanlat JF, coordenador. O indivíduo na organização: dimensões esquecidas. 3 a ed. São Paulo: Atlas; 1996. v.3. p.127-47.

2. Elias N. Sobre o tempo. Traduzido por Ribeiro V. Rio de Janeiro: Jorge Zahar; 1998.

3. Whitrow GJ. O tempo na história: concepções do tempo da pré-história aos nossos dias. Traduzido por Borges MLXA. Rio de Janeiro: Jorge Zahar; 1993.

4. Hassard J. Tempo de trabalho: outra dimensão esquecida nas organizações. Traduzido por Rodrigues AM. In: Chanlat JF, coordenador. O indivíduo na organização: dimensões esquecidas. São Paulo: Atlas; 1992. v. 1, p.175-93.

5. Gasparini G. Tempo e trabalho no ocidente. Traduzido por'Tôrres OLS. In: Chanlat JF, coordenador . O indivíduo na organização: dimensões esquecidas. São Paulo: Atlas; 1996. v.3. p.111-26.

6. Schoeps W. Estudo dos tempos e movimentos. In: Machline C, Motta IS, Schoeps W, Weil KE. Manual de administração da produção. 9a ed. Rio de Janeiro: Fundação Getúlio Vargas; 1990. v. 2. p. 480-523.

7. Gaither N, Frazier G. Administração da produção e operações. 8a ed. Traduzido por Santos JCB. São Paulo: Pioneira Thomson; 2001.

8. Slack N, Chambers S, Harland C, Harrison A, Johnston R. Administração da produção. Traduzido por Brandão AB, et al. São Paulo: Atlas; 1999.

9. Pires D. Reestruturação produtiva e trabalho em saúde no Brasil. São Paulo: AnnaBlume; 1998.

10. Medici AC, Girardi SN. Emprego, remuneração de pessoal e produtividade em saúde: um balanço da literatura recente. Divulg Saúde Debate. 1996; (14): 38-43.

11. Bittar OJNV. Produtividade em hospitais de acordo com alguns indicadores hospitalares. Rev Saúde Pública = J Public Health. 1996; 30(1): 53-60.

12. Mello MC. O estudo do tempo no trabalho da enfermagem: construção de instrumento de classificação de atividades para implantação do método amostragem do trabalho [tese]. São Paulo: Escola de Enfermagem da Universidade de São Paulo; 2002. 